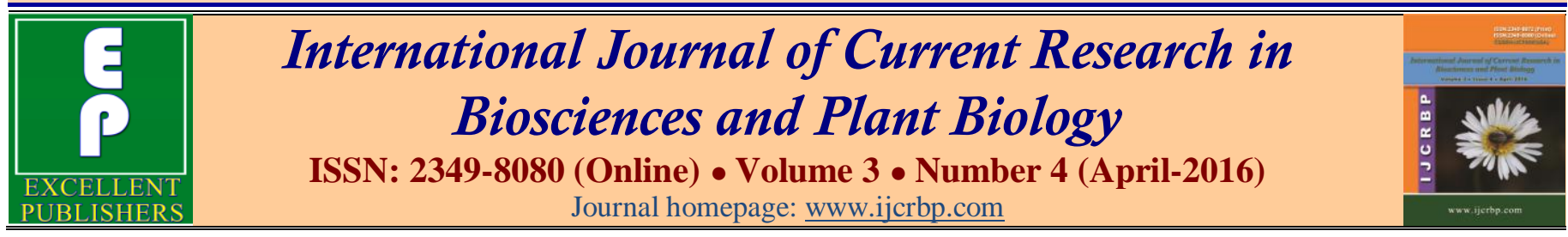

Original Research Article

doi: http://dx.doi.org/10.20546/ijcrbp.2016.304.007

\title{
Organic Cultivation of Medicinal and Aromatic Plants: A Case from Uttarakhand Himalaya, India
}

\author{
Arvind Bijalwan* \\ Indian Institute of Forest Management (IIFM), Nehru Nagar, Bhopal-462 oo3, Madhya Pradesh, India \\ *Corresponding author.
}

\begin{abstract}
A bstract
The project on income generation of BPL farmers through cultivation of medicinal and aromatic plants in Tehri district of Uttarakhand, India was implemented by Matrichhaya Parvatiya Vikas Samiti (MPVS), a voluntary Non Governmental Organization during 2004-07. The cultivation of aromatic plants Geranium (Pelargonium graveolens) and Lemongrass (Cymbopogon flexuosus) were taken in organic manner with construction of vermin-compost unit at each household. The farmers not only used the vermicompost in geranium and lemon grass but also used in agricultural crops and also sold the vermicompost and earthworms to the market and generated the income.
\end{abstract}

\section{Article Info}

Accepted: 14 March 2016

Available Online: 06 April 2016

\section{Ke ywords}

Geranium

Income generation

Lemon grass

Medicinal and aromatic plants

Organic farming

Vermicompost

\section{Introduction}

Geranium scientifically known as Pelargonium graveolens is an aromatic shrub belongs to family Geraniaceae. This plant is commonly known as rose scented Geranium as the leave of the plant produce the fragrance of rose. This perennial shrub grows to approximately a meter tall and thrives in a low-humidity and diverse climate. Geranium provides essential oil and the oil is mainly characterized by presence of geraniol, citronellol, linalool and broad range of esters, in addition the oil also contained many sesquiterpenes (Verma, et al., 2010; Fraisse et al., 1983; Gomes et al., 2007). Lemon grass (Cymbopogon flexuosus) is an aromatic plant belongs to grass family Poaceae (Akhila, 2010) is similar to other grasses but its scented smell of lemon makes it different from other grasses.

Geranium and Lemon grass are popular for aromatic oil and used as ingredient in soap, shampoo, tooth paste, hair oil, perfume, cosmetic cream and in medicinal industry. The present study was conducted under a special project for Income generation through cultivation of medicinal and aromatic plants to the farmers of Tehri district of Uttarakhand, India, implemented by Matrichhaya Parvatiya Vikas Samiti (MPVS), a voluntary Non Governmental Organization at Gaja Tehri Garhwal, Uttarakhand, India during 2004-07. The project was jointly funded by Ministry of Rural Development, Government of India and Rural Department, Government of Uttarakhnad with a aim to generate the income of 2000 Below Poverty Line (BPL) farmers of district Tehri Garhwal. The project was implemented in three phases with a selection of 400,800 and 800 beneficiaries in first, second and third phases/years respectively.

In order to safe use of biodegradable waste and enhance the organic and sustainable farming, the construction of vermicopost pits were done on the agricultural fields of farmers to practice the use of vermicompost in place of chemical fertilizers. Interestingly the lemon grass was taken under cultivation through organic manner keeping its easy growth, market demand and economic values. 


\section{Selection of medicinal and aromatic plants}

The different farmers of Below Poverty Line (BPL) were selected from the selected blocks of district Tehri Garhwal, Uttarakhand, India. The concept of the project was to generate the income of rural poor through cultivation of Medicinal and Aromatic Plant. Since the synthetic fertilizer is also being used by the farmers therefore, the sole objective of the project was to organically cultivate the medicinal and aromatic plants. While the project was started a big challenge was to select the medicinal and aromatic crop for the hilly terrain which can grow in the rain-fed area, crop compatible to geographically situation, less hazardous by the wild animals and highly remunerative having good demand and easily salable/marketable by the farmers. In the above context the two important aromatic crops viz Geranium and Lemon grass were finally selected in consultation with the cultivators and scientific community.

\section{Selection of beneficiaries and name of SHGs}

The project was implemented in three phases with formation of Self Help Groups (SHG) or Swayam Sahayata Samuha of the beneficiaries with the number of beneficiaries varies from 7 to 20 in each SHG including Women, Schedule Caste, Schedule Tribe, Physically disable and other rural poors (BPL). The name of the SHGs was selected on the name of medicinal and aromatic plant and their varieties. The accounts of the SHGs were opened in the nearest bank with the help of President, Voice President and Secretary of the SHG. The name of some important SHGs were- Neelkanthi Swayam Sahayata Samuha- Gaunsari, Kutaki Swayam Sahayata Samuha-Dubakoti, Chirayata Swayam Sahayata Samuha- Pali, Hina Swayam Sahayata Samuha- Bhali, Ashwagandha Swayam Sahayata Samuha- Birogi, Ghritkumari Swayam Sahayata Samuha- Naicholi, Tulsi Swayam Sahayata SamuhaKulpi, Snajeevani Swayam Sahayata Samuha- Jagethi, Bramhi Swayam Sahayata Samuha- Kathur, Atis Swayam Sahayata Samuha- Bamangaon, Shankpushpi Swayam Sahayata Samuha- Khadwalgaon, Satavari Swayam Sahayata Samuha- Gaind, Ratanjot Swayam Sahayata Samuha- Khand, Arjun Swayam Sahayata Samuha- Tipli, Amaltas Swayam Sahayata SamuhaRampur, Chitrak Swayam Sahayata Samuha- Kafolgaon, Kedarpati Swayam Sahayata Samuha- Kudi, Koot Swayam Sahayata Samuha- Bamangaon, Kantkari Swayam Sahayata Samuha- Gandi, Giloa Swayam Sahayata Samuha- Nala, Sumaiya Swayam Sahayata
Samuha- Koti, Krishna Swayam Sahayata Samuha- Pali Kakarasari, Chirharit Swayam Sahayata SamuhaAampata, Banapsa Swayam Sahayata SamuhaAndarphi gaon, Bajradanti Swayam Sahayata SamuhaDabada, Pipli Swayam Sahayata Samuha- Jaykot, Tejpat Swayam Sahayata Samuha- Falsari likewise Geranium Swayam Sahayata Samuha, Lemongrass Swayam Sahayata Samuha, etc.

\section{Trainings and demonstration to the farmers}

\section{Mother unit}

Since the Geranium, Lemongrass and medicinal and aromatic plants were new to the farmers therefore, the inhouse training and demonstration were provided constructing a Mother Unit having a centrally located Mother nursery. The Mother Nursery was established in Amaltas Nagar, village Gaind which was the centre part of most of the beneficiaries' villages. The area for mother nursery was taken on lease basis from the villagers covered five hectare (250 nali as per local unit; as 1 hectare $=50$ nali). The all works related to field Preparation including maintenance of fields and construction of retaining wall was done with the help of local villagers and provided employment to the local people. The following other facilities were generated in the mother units:

- Nursery beds were prepared

- Establishment of pipe line

- Construction of water tanks and establishment of irrigation system

- Construction of poly houses

- Establishment of shed nets for the initial growth of the seedling

- Mother block of Lemon grass and Geranium was developed for the demonstration purpose

- The other medicinal plants/seedlings were established

- Vermicompost pits were Constructed for demonstration

- Development of Micro irrigation system

- High teach mist chamber

- Unit for preparation of slips, cuttings and poly bag plants

\section{Resource Center}

The Resource Centers were also developed having area of about one hectare (50 nali) in the region basis 
to provide training and demonstration to the farmers in the nearest area from their villages. In the resource centers the technical resource persons were also recruited to train the farmers. The resource persons were selected who can speak in local language (Garhwali) however the trainings and exposure visits were also provided to the resource persons in different research and training centers of Medicinal plants.

\section{Training and exposure visits to BPL farmers/ beneficiaries}

Almost all the farmers were given training and exposure visits to different medicinal plant research centre and Institutions, moreover complete training to the beneficiaries were given in Mother Nursery, Amaltas Nagar with the experts invited from different medicinal research centre, Institutes and Universities.

\section{Support provided to the farmers and activities on the farmers field}

The technical support was provided to the farmers for preparation of their filed as per the following steps:

- Soil samples testing of beneficiaries' field was done.

- Provided technical know-how in ploughing and bed preparation at beneficiaries field.

- Supply of organic insecticide, pesticide, etc.

- Supplied of vermicompost (kechua khad) in the initial stage.

- Distributed Geranium cutting/rooted seedlings and Lemongrass slips to the beneficiaries as per the land spared for the cultivation on their farmland.

\section{Construction of vermicompost unit}

The Cemented Vermicompost pits made-up of bricks were constructed on the agricultural field of every selected farmer. The pits were constructed in modern pattern with two partitions each comprised of $10 \mathrm{ft}$ in length, $3 \mathrm{ft}$ in width and $1.75 \mathrm{ft}$ in height. The required amount of red earthworms (Eisenia fetida) was also provided to the farmers. In order to maintain the humidity in the pit and to protect it from direct sunlight and rainfall the pits were covered with proper clothing provided by the MPVS organization. The frequent advises were also given to the farmer for making pits suitable for speedy decomposition of raw material.

\section{The experience and income generation by the farmers}

The area of Garhwal Himalayan region is predominated by rainfed situation (depend upon rain only for irrigation) and no other alternative of irrigation are usually available there. In the initial phase the farmers were little hesitant when they invited to cultivate the Geranium, Lemongrass and other medicinal and aromatic plants on their farm land, however, after acquainted with the medicinal plants and technology involved in the cultivation of these plants (Geranium and Lemon grass) they expressed their willingness to cultivate in the more area/land. The reason being, the aromatic plants were very easy to cultivate, having good production potential. The vermicompost, was a new intervention to the farmers but when they trained and seen the effect of vermin-compost on growth and development of plants, also appreciated it and applied the vermin-compost in their agricultural crops too.

Every SHG with 7 to 20 farmers/beneficiaries in each group cultivated the Geranium and lemongrass using vermin-compost (organic cultivation) as fertilizer. The farmers cultivated the Geranium and lemongrass and produced significant amount of Geranium and lemongrass herbage. The farmers also sold the Geranium cuttings and Lemongrass slips as planting material and earned handsome amount. The farmers also earned the money through selling vermicompost and red earthworms. This project was proved good for the farmers of rainfed areas where the productivity is very low and the farmers are busy in the agricultural activities all through the year and hardly earn the money to make them self-sufficient.

\section{Conflict of interest statement}

Author declares that he has no conflict of interest.

\section{Acknowledgements}

The author is grateful to the Ministry of Rural Development, Government of India and Department of Rural Development, Government of Uttarakhand for jointly funded the project titled "Rural employment assurance through entrepreneurship development in cultivation of medicinal and aromatic plant in Uttaranchal" under SGSY special project scheme to Matrichhya Parvatiya Vikash Samiti (MPVS), Gaja, Tehri Garhwal, Uttarakhand, India. The author is extremely thankful to Mr. Aditya Kothari, Chairman, 
MPVS for his support and untiring efforts to implement this projects. Thanks are also due to national, state and district level administration for supporting in implementation of the project. The MPVS team and BPL beneficiaries/farmers of the project area are greatly acknowledged.

\section{References}

Akhila, A., 2010. Essential Oil-bearing Grasses: The genus Cymbopogon. Medical and aromatic plants-industrial profile. Taylor and Francis Group, L.L.C.

Fraisse, D., Scharf, C.S., Vermin, G., Metzer, J., 1983. SPECMA Bank application to the study of geranium essential oils of various origins, IXth international Essential Oil congress, Singapore, Technical paper, Book 3. pp.100-120.

Gomes, P.B., Mata, V.G., Rodrigues, A.E., 2007. Production of rose geranium oil using supercritical fluid extraction, J. Supercrit. Fluids. 41, 59-60.

Verma, R.S., Verma, R.K., Yadav, A.K., Chauhan, A., 2010. Changes in essential oil composition of rose-scented geranium (Pelargonium graveolens L' Herit. Ex Ait.) due to date of transplanting under hill condition of Uttarakhand. Indian J. Nat. Prod. Resour.1(3), 367-370.

\section{How to cite this article:}

Bijalwan, A., 2016. Organic cultivation of medicinal and aromatic plants: A case from Uttarakhand Himalaya, India. Int. J. Curr. Res. Biosci. Plant Biol. 3(4), 39-42.

doi: http://dx.doi.org/10.20546/ijcrbp.2016.304.007 